\title{
Examining the Effects of Decomposed Perceived Risk on Consumer Online Shopping Behavior: a Field Study in China
}

\author{
Yue Chen ${ }^{1}$, Xiangbin Yan ${ }^{1}$, Weiguo Fan $^{2}$ \\ ${ }^{1}$ Harbin Institute of Technology \\ No.13 FaYuan Street, 150001, Harbin, China \\ E-mail.chenyue1984@gmail.com,xbyan@hit.edu.cn \\ ${ }^{2}$ Department of Accounting and Information Systems, Virginia Tech \\ 3007 Pamplin Hall, VA 24061-0101, Blacksburg, USA \\ E-mail.wfan@vt.edu

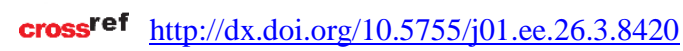

\begin{abstract}
Perceived risk research has drawn much attention in recent years. In investigating the roles that perceived risk plays in consumers' online purchasing behavior, most of the studies viewed perceived risk as high-level surrogate construct, and a few focused on one or several risk facets. Few studies, however, distinguished how different sources of perceived risk influence consumers' purchase behavior. We thus seek to fill this research gap in this study. Based on value transfer process and components, we theoretically decompose online purchase perceived risk into three major source components: uncertainty of transaction cost, product performance and consumer's individual anxiety, and propose how they bring their respective impacts to consumers' purchase behavior. By introducing some other online shopping involved factors as control part, we propose a more comprehensive conceptual research model. Empirical results from a field survey in China shows that different sources of perceived risk bring distinct effects to purchase behavior. Perceived risks from individual anxiety were found to have significant influences on consumers' satisfaction and re-purchase intention, while risks from transaction cost affect only satisfaction. Moreover, risks perceived from product performance were even found to have positive impact on re-purchase intention. Our study provides insights into how different sources of perceived risk influence consumers' purchase behavior.
\end{abstract}

Keywords: decomposed perceived risk; satisfaction; re-purchase intention; online shopping; consumer behavior.

\section{Introduction}

The dramatic explosion of e-commerce has called for considerable research on consumer behavior in the past decade. Among various research topics, perceived risk related to online shopping is a central issue. Earlier perceived risk research mainly focused on the concept of perceived risk itself, investigating the essence of perceived risk, the definition, the components and the measurement (Bauer, 1960; Cunningham, 1967; Dowling, 1986; Jacoby \& Kaplan, 1972). Later research paid attention to the influence perceived risk brings to customers' behaviors, using the paradigms of perceived risk- perceived benefit, or extending TAM or TPB model with trust-risk considerations (Featherman \& Pavlou, 2003; Kim, Ferrin, \& Rao, 2008; Luo et al., 2010). These studies either viewed perceived risk as a high-level surrogate construct or chose several risk facets to represent the concept of perceived risk. The results, consequently, either confirmed the overall negative role that perceived risk played or examined the significance of the chosen facets in respective research, with conclusions too general or too limited. A few studies have tried to give classification to perceived risks that exist in online environment (Dowling, 1986; Lim, 2003) . These studies, however, were all conceptually based. From the point of getting quantitative results to support decision making demand, little work has been done to provide a concise but holistic way to decompose risks or to provide convincing results of how different components of perceived risk bring influences, especially for online shopping.

We thus seek to fill in this research gap by proposing a new simplified classification scheme for perceived risk to detailed and quantitatively investigate its roles. We propose to decompose the perceived risk into three sub-dimensions based on value transfer and then empirically explore their respective roles in influencing consumer online purchase behavior. We believe our research on the impacts of decomposed risks of online consumer behavior will enrich existing stream of research on perceived risk, and help Internet vendors to better understand consumers' online purchase hesitation in practice. By confirming these influences, the vendors will offer more considerate service based on consumers' needs, which can help them get more success in business. Specifically, our research would like to make three main contributions to the existing body of research related to perceived risk. Firstly, built upon value transfer process in retail market, we proposed to decompose perceived risk into three components: the product performance risk, individual anxiety risk perception and transaction cost risk. This decomposed method makes the multi-dimensions of perceived risk complete but not overlapped. Secondly, using well-known IS success factors - information quality, system quality and service quality, perceived benefits as control variables, we develop a research model to examine 
how each proposed dimension of perceived risk influences consumers' online purchase behavior. Moreover, we empirically tested the model, and provide findings and insights about consumer behavior in a unique Chinese cultural setting. We collected data from a field survey using subjects in China since China has witnessed a tremendous growth in e-commerce recently and its growth and progress has many unique characteristics: to name a few, product quality uncertainty (the prevalence of "Shanzhai" imitating products), flexible payment method (payment on delivery vs. payment upfront), cheap and fast growing shipping/ delivery chains. These unique characteristics are not common in the western world, which makes us believe that Chinese people may experience different risk factors in online shopping. Our results showed that each decomposed risk factor acted differently to consumer purchase behavior. One of the risk factors, product risk, even had a surprising positive effect on consumer purchasing behavior. Thirdly, we have also examined the impacts of control variables-perceived benefit, service quality and website quality that might affect consumer's online shopping behavior. Our results show some findings that are lightly contrary to the conventional wisdom of thoughts and we offer our interpretations and implications as well.

\section{Theoretical Backgrounds}

\section{Outcome variables: customer satisfaction and re-purchase intention}

Consumer's purchase behavior refers to the process by which individuals search for, select, purchase, use, and dispose of goods and services, in satisfaction of their needs and wants (Howard \& Sheth, 1969). The Theory of Reasoned Action (TRA), the Theory of Planned Behavior (TPB) and the Technology Acceptance Model (TAM) have pointed that consumers' attitudes and intention can effectively predict their actual behaviors (Ajzen, 1991; Bhattacherjee, 2001; Davis, Bagozzi et al., 1989). The Expectation-Confirmation Model (ECM) states that consumers' post-purchase satisfaction and re-purchase intention derives from their expectations and confirmations (to products or services) (Bhattacherjee, 2001). Meanwhile, DeLone \& McLean's IS Success Model states that information quality, system quality are the main factors determining user's satisfaction and intention to use (DeLone \& McLean, 1992). In sum, consumers' overall satisfaction and intention to continue using the internet for purchasing (re-purchase intention) are effective proxy factors for consumers' purchase behavior. Hence, we use these two variables as our study dependent variables.

\section{Theory of perceived risk}

In the marketing research, risk is conceptualized as involving two elements: uncertainty and consequences. Bauer argued that consumers' behavior involved risk because their purchasing actions "will produce consequences which he cannot anticipate with anything approximating certainty, and some of which at least are likely to be unpleasant" (Bauer, 1960). Early studies defined consequences as losses (Cox, 1967), but a more recent measurement approach considers a more integrated conceptualization of risk as the expectation and importance of losses (Mowen, 1992; Venkatraman, 1989). Generally, perceived risk is viewed as a consumer's level of uncertainty with regards to the outcome of a purchasing decision. "Consumers are more often motivated to avoid mistakes than to maximize utility in purchasing" (Mitchell, 1999). Perceived risk is thus powerful at explaining consumer's purchase behaviors. The more risk they perceive, the less likely they will repurchase online.

Online transactions are inherently more uncertain than brick-and-mortar purchases because of consumers being distant spatially (and sometimes temporally) from their purchases as well as the unpredictable nature of the Internet transactions (Brynjolfsson \& Smith, 2000). These factors, in turn, translate into consumers' perception of more risks, less satisfaction, and, more generally the reluctance to buy online (Pavlou, 2003). Consumers' uncertainties mainly come from three aspects: first, consumers worry about that the items purchased online may not deliver the expected benefits (Glover \& Benbasat, 2010); secondly, consumers worry about that functionalities offered by an Internet site to facilitate or enhance the primary service of the site might require too much time, too much effort, or too much money; third, customers worry about that information revealed in the course of an e-commerce transaction might be misused (Culnan \& Armstrong, 1999). In sum, the open nature of the Internet as a transaction infrastructure and its global nature creates uncertainties around on-line transactions, and this makes risk one of the crucial elements of e-commerce (Hoffman et al., 1999).

\section{Existing perceived risk classifications and limitations}

The means of giving out the dimensions of perceived risk is significant because it deals with the measurement of perceived risk. One research stream investigated risk dimensions from a consequence perspective and identified nine dimensions of the risk consequences: financial risk, performance risk, physical risk, psychological risk, time loss risk, personal risk, privacy risk and source risk (Jacoby \& Kaplan, 1972; Jarvenpaa \& Todd, 1996; Roselius, 1971; Simpson \& Lakner, 1993). The roles that each dimension played were confirmed various in each respective research, e.g., Jarvenpaa and Todd identified five of these types of risk in online shopping and got support that personal risk and performance risk were more important than financial, social and privacy risk (Jarvenpaa \& Todd, 1996), while only financial risk was found significant in Simpson and Lakner's research (Simpson \& Lakner, 1993). Another research stream examined the different roles perceived risk plays in product involvement search. The perceived risk was found to have involvement, consequence, antecedence and moderator relationships with the search (Jarvenpaa \& Todd, 1996; Oliver, 1980). Meanwhile, it is necessary to identify the effects of different types of risks in business if they want to reduce consumers' perceived risk. The consequence classification, however, has the problems with unclear definition and fails to show the source of perceived risk (Lim, 2003). Thus, Lim later proposed a new classification perspective- from 
the source dimension. Lim defined the different sources of risk as the degree to which individuals believe that if they purchase products or services through the Internet, they will suffer loss from this source. In her research, vendor, technology, consumer and product are proposed to be the sources of the consumers' perceived risks in relation to online shopping. By her classification, each consequence dimension has overlapped attributes to different sources dimensions, e.g. perceived financial risk can come from vendor, technology or product; and different consequences dimension might have the same sources, e.g., psychological risk and time-loss risk have the same source with financial risk. Moreover, different source dimensions - technology, vendor, consumer and product are not mutually exclusive. All of these made Lim's classification is conceptual based but not feasible in quantitative research. From the perspective of getting quantitative result support, this classification method needs to be improved. A method which can effectively decompose perceived risk to better understand consumers' online shopping behavior desirable.

\section{Research Design}

\section{A new risk classification scheme based on value transfer}

From the value transfer perspective, we propose a new classification method for perceived risk in online shopping.

Consumer-vendor's online purchase-sale activity is a form of transaction. A transaction is a process by which a commodity or service is transferred across a technologically separable interface - always from the vendor to customer (E, 1985). It is in fact a value transfer process, whilst transaction cost is added as part of value in the stream of activities involved in providing e-commerce to the consumer (Barnes, 2002). A transaction comprises three major components: purchased products, people, and the transaction process. Consumers' perception toward purchased value includes product value as well as the process and channel choosing cost. Product is the target of a transaction activity; it is the origin of consumer's purchase intention and expectation. The involving people, customers and vendors, are the transaction subjects-- who conduct the purchase. The transaction process is the medium by which the value of the product is transferred from the vendor to the customer (Liang \& Huang, 1998). These three components cover all the transaction involving elements, and each element is exclusive of each other. Risk perceptions coming with a transaction can thus be decomposed based on this paradigm. Perceived risk is accordingly decomposed to product risk, people risk and transaction process risk.

Note that the people involved in a transaction include both the customer and vendor. However, as the transaction continues, vendor related risks, including service risk and product risk, are subsumed by transaction process (such as time loss in transaction cost risk if product delivery delayed) and product (such as product risk for defective or fake products). Hence, the people related perceived risk during a transaction should include only the customer's individual risk. This leaves us with three major transaction component related risks: perceived transaction cost risk, perceived product risk and perceived individual (customer's) risk. Table 1 shows how the proposed transaction components dimensions match the existing consequences dimensions.

By decomposing perceived risk in accordance with the participants in a transaction, this classification method clearly attributes the risks to their sources. With no overlapping among these three risk sources, this classification method also meets the requirement of conducting empirical examination, which requires the research subjects should be distinct from each other. By doing quantitative analysis, it will help vendors to locate where the risks comes from and how they bring influences to consumers' purchase behaviors.

Table 1

Perceived risk-consequence and transaction elements matched

\begin{tabular}{cccc}
\hline \multirow{2}{*}{ Consequence } & \multicolumn{3}{c}{ Transaction Components } \\
\cline { 2 - 4 } & Transaction Cost & Product & Individual \\
\hline Financial & $\sqrt{ }$ & $\sqrt{ }$ & \\
Performance & & $\sqrt{ }$ \\
Social & $\sqrt{ }$ & $\sqrt{ }$ \\
Physical & & & $\sqrt{ }$ \\
Psychological & & & $\sqrt{ }$ \\
Time-loss & & & \\
Personal & & & \\
Privacy & &
\end{tabular}

\section{Research model and hypotheses development}

Based on the newly proposed dimensions of perceived risks, we next elaborate on how these three classified perceived risks relate to consumers' online purchasing behaviors. In order to capture the role of each dimension more precisely in comparison with known influencing factors, we introduced three other online purchasing factors-- perceived benefit, service quality and website quality as control part (more on this later). A whole framework of investigating the effect of decomposed perceived risk is proposed, as shown in Figure 1.

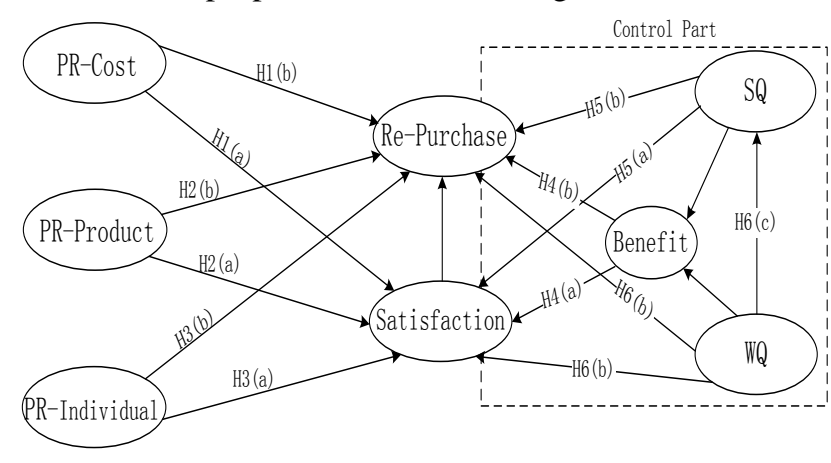

Figure 1. Conceptual research model

\section{Perceived transaction cost risk}

From the economic point of view, economic factors for a consumer to purchase over the web instead of a traditional store can well explain his/her acceptance of online shopping. When customers purchase a product from a seller, they must go through a series of steps. This is called a transaction process. Given that the information is 
always asymmetry between vendors and customers, consumers should conduct activities such as searching for information, negotiating terms or monitoring the on-going process to dodge the potential risks like price deception, exaggerated product description or some other risks (Coase, 1988). The costs involved with such transaction-related activities are called transaction costs. Transaction cost economics (TCE) theoretically explains why a transaction subject chooses a particular form of transaction instead of others. The basic principle of TCE is that people like to conduct transactions in a way that minimizes their transaction cost (Williamson, 1981). A customer will go with a channel that has lower overall transaction cost during a transaction process(Liang \& Huang, 1998).

The transaction cost risk refers to the money lost or price immoderate, time spent, channel inherent risk and product receivable risk that exist in the chosen buying channel. Compared to traditional transactions, online purchase holds the negative characteristics of lack of contact, delay of product receivables, complexity in technologies, etc. (Bhatnagar, Misra, \& Rao, 2000). These characteristics are the cost that consumers bear for the purchase choice while enjoying advantages that online shopping brings. Though businesses have developed new technologies and protocols, this transaction cost itself is still the main source that brings consumers' risk (Greenstein \& Feinman, 2000). An over high perceived transaction cost, e.g., too much time spent in searching and comparing products and long delivery periods, will offset the benefit that online purchase brings. Consumers' satisfaction will be consequently decreased, which results in a lower re-purchase intention and makes the consumers tend to look for other purchase channels instead. Generally, the more transaction cost is thought to exist in the purchase channel, the higher transaction cost risk is perceived, and the lower desire will be shown for this mode of purchase. Hence, we propose that:

$H 1$ (a): Perceived transaction cost risk (PR-Cost) has negative effect to consumers' overall satisfaction;

$H 1$ (b): Perceived transaction cost risk (PR-Cost) has negative effect to consumer's re-purchase intention.

\section{Perceived product risk}

Product risk refers to the risk perceived from product performance, quality and value. Consumers' anxieties towards usefulness or functionality of products constitute this dimension of perceived risk (Lim, 2003). Utility maximization is one principle for consumers making purchase decision (Zeithaml, 1988). Consumers hope the products can meet their demand and be in good quality or value, and will show satisfaction and willingness to purchase when products meet or exceed expectations. In reality, however, this ideal situation cannot always be promised. On one hand, insufficient information obtained makes consumers doubt about the product quality, and ambiguous warranty policy even makes the product feel more risky. The uncertainty toward product performance decreases customer's purchase intention. On the other hand, due to the intangibility of products, some customers hold anxieties that the products may be inappropriate to their needs (Bhatnagar et al., 2000). The flourishing oversea online shopping even makes this question become more relevant, since the standardizations are varied in each country. Customers who had similar experiences will probably feel less satisfaction and lower the intention of re-purchase. Product value is another important factor that constitutes product risk. In an interview about attitude toward online shopping perceived risk, participants indicated that they were worried that the received product does not meet the value as they expected and were always more cautious when buying expensive items through the Internet, because high value means a possible high loss when risk actually happens. Worried about the true product value, consumers tend to limit their purchase. In general, high perceived product risks decrease customer's satisfaction and probably lower the intention to re-purchase. Thus, we propose that:

H2 (a): Perceived product risk (PR-Product) has negative effect to consumer's overall satisfaction;

H2 (b): Perceived product risk (PR-Product) has negative effect to consumer's re-purchase intention.

\section{Perceived individual risk}

Perceived individual risk refers to the negative physical or psychological influence that consumer perceived when conducting online purchase. The individual risk includes consumers' emotional pressure, physical health risk, and privacy concerns. An underlying premise of this approach is that different individuals would have different levels of risk acceptance (or aversion) (Bhatnagar et al., 2000), and these differences are the probable inherent reasons for different purchase behavior. Consumers are worried about the potential loss of self-esteem from the frustration of not achieving a purchase goal (Pires et al., 2004). The risk in regards to the selection or performance of the producer will have a negative effect on the consumer's peace of mind or self-perception (Mitchell, 1992), i.e., a consumer is likely to feel frustrated if their purchase are unsuccessful, and, in consequence, lower their satisfaction. Consumers are also worried that their physical health may be influenced by online purchase and consequently intend to do less online purchase(Jarvenpaa \& Todd, 1996). Social pressure refers to the pressure individuals receive from their families, friends, or colleagues(Fishbein \& Ajzen, 1975). The theory of reasoned actions points that social influence has a direct effect on behavioral intention(Fishbein \& Ajzen, 1975). The more social support individuals garner regarding their actions, the more likely they will perform the action, vice versa. A rational customer tends to decrease the possibility to conduct a purchase when a high level of individual risk is perceived. Hence, we propose

H3 (a): Perceived individual anxiety risk (PRIndividual) has negative effect to consumer's overall satisfaction;

H3 (b): Perceived individual anxiety risk (PR-Individual) has negative effect to consumer's re-purchase intention. 


\section{Control Part}

The ultimate dependent variables - consumers' overall satisfaction and re-purchase intention, have been found to be influenced by several other factors in addition to the risk factors as explicitly hypothesized in existing studies, e.g. information quality, system quality and service quality (Bhatnagar et al., 2000; Delone, 2003). Without these factors, an incomplete purchase behavior model contains only risk that might exaggerate the influence of risk factors and overlook other effects. It thus requires us to comprise these factors in our research model. In addition, since this study is an exploratory research toward Chinese consumers, we would like to verify whether these relationships remain in Chinese culture. Given that the focus of this research is investigating the role of each decomposed perceived risk factors but not all the involved elements, we introduced them as control part in our model. We next provide further details about the control part.

Perceived benefit (Benefit) (Zeithaml, 1988) conceptualized perceived benefit as "the consumer's overall assessment of the utility of a product based on perceptions of what is received and what is given." It is generally found that the more benefit consumers perceived, the more likely high level of satisfaction and re-purchase intention will be formed (Kazakeviciute \& Banyte, 2012; Yang \& Peterson, 2004). Hence, we introduce perceived benefit in research model and propose that:

H4 (a): Perceived Benefit has positive effect on consumer's overall satisfaction;

H4 (b): Perceived Benefit has positive effect on consumer's re-purchase intention.

Service quality (SQ) and Website quality (WQ)

The IS Success Model investigated the determinants and measurement of information systems success and has been widely adopted in IS and related research. According to IS Success Model, information quality, system quality and service quality are the antecedents of user's satisfaction and re-use intention toward IT applications or products (Delone, 2003). Apart from the product quality, consumers wonder if the vendor can provide thoughtful service which plays a great role in establishing their word-of-mouth and keep their customers' loyalty (Verhagen \& van Dolen, 2011). The services are always evaluated by customers from perspectives of security, after-sale service guarantee, and historical reputation (Salciuviene, Auruskeviciene, \& Ivanauskiene, 2014). "Its importance is most likely greater than previously since the users are now our customers and poor user support will translate into lost customers and lost sales" as stated by Delone and Mclean when they introduced the IS Success Model to E-commerce (Delone, 2003).

Meanwhile, information quality and system quality are always combined perceived as website quality in e-commerce transactions by customers. Research results have shown that the website reputation, information quality, user interface quality, and security perceptions were observed to affect information satisfaction and relational benefit, which, in turn, were significantly related to each consumer's site commitment and actual purchase behavior (J. Cox \& Dale, 2002; Ethier et al., 2006). Whilst website quality is usually viewed as part of service quality by consumers, it might thus bring effect to service quality. Taken together, we employed service quality and website quality in our research model and proposed that:

H5 (a): Service quality has positive effect on consumer's overall satisfaction;

H5 (a): Service quality has positive effect on consumer's re-purchase intention;

H6 (a): Website quality positively affects consumer's overall satisfaction;

H6 (b): Website quality positively affects consumer's re-purchase intention;

H6 (c): Website quality positively affects service quality.

In addition, as major components of vendor's service, the service quality and website quality undoubtedly influence consumers' perception of what is provided. It is reasonable to speculate that service quality and website quality have impacts on consumers' perceived benefit. Taken with prior assumptions, perceived benefit, possibly mediates the relationships between service/website quality and satisfaction/re-purchase intention. We then added links between service/website quality and perceived benefit to see whether these mediating roles exist.

\section{Research method}

\section{Instrument development}

To test the theoretical framework, a questionnaire survey was used to gather data. A thorough review of the literature on the subject of the study was conducted to ensure content validity. The questionnaire was pilot tested by having a panel of IS and Marketing experts review it, after which necessary changes were made to improve both the content and clarity of the questionnaire. Next, a sample of respondents $(n=49)$ separate from those included in the pilot test was asked to check the questionnaire. These and all pilot test respondents were excluded from the main sample. The principal constructs were developed based on existing measures when possible or on similar scales. The measures comprised Likert-type statements, measured on seven-point scales ranging from "totally disagree" to "totally agree". And for some other items, the score was asked to be rated from 1 to 7 , also a seven-point scales.

The construct of three perceived risk factors were treated as formative constructs, whilst re-purchase intention, service quality and website quality were treated as reflective constructs (see Table 2). A reflective construct indicates that measurement indicators are observed as functions of the latent variable, whereby changes in the latent variable are reflected in changes in the observable indicators. Formative construct is often termed as a combination variable or composite variable (MacKenzie et al., 2005). This means that the measures cause the construct and that the construct is fully derived by its measurement. Here, formative representation is preferred over reflective to the construct of perceived risk because the increase in one risk dimension such as perceived social risk does not necessarily cause an increase in other types of perceived risks (performance risk, financial risk, etc.). 
Consumers' various risk anxieties toward online shopping were asked and used as the proxy variables for consumers' perceived risk in this research. Re-purchase intention was measured using reflective indicators covering one's future willingness to buy online and word of mouth recommendations. A high level of website quality or service quality requires good performances in each related aspects, hence reflective measure was employed. Consumer satisfaction has been studied extensively and often been treated as the single most important construct that determines consumers' subsequent behavior(Richard L
Oliver, 1999). Single-item Likert scales from "very satisfied" to "very dissatisfied" responses are employed to measure the consumers' overall satisfaction. According to Jarvis' construct identify requirement, all the constructs can be identified by proposed model (Jarvis et al., 2003). Table 2 gives out the constructs, the items finally employed to measure them, and the sources where they were adapted. In accordance with conceptual model design, all the questions are asked about overall perception toward experience based online shopping.

Construct and indicators.

\begin{tabular}{|llll|}
\hline Construct & & \multicolumn{1}{c|}{ Indicators } & Indicators Type \& Adapted From \\
\hline & Cost & R1: Price & \\
& & R2: Delivery delay or fail & \\
& & R3: Time loss in choosing product & \\
& Product & R4: Quality & Formative \\
Perceived Risk & (PR-Product) & R5: Lack of good feel of product & 1972; Kwak, Fox, \& Zinkhan, 2002) \\
& & R6: Value & \\
& Individual Anxiety & R7: Health & \\
& (PR- Individual) & R8: Privacy & \\
& & R9: Social pressure & Single (Shim \& Mahoney, 1992) \\
Satisfaction & & Overall Satisfaction & Reflective \\
Re-Purchase & & Purchase possibility & (Gefen, 2000; Narayandas, 2005) \\
Intention & & Loyalty & Single (Zeithaml, 1988) \\
Perceived Benefit & & Overall benefit perceived & Reflective \\
Service Quality & & SQ1: Reputation & (Yan \& Dai, 2009) \\
(SQ) & SQ2: Privacy Promise & Reflective \\
& SQ3: After-sale services & (Park \& Kim, 2003) \\
Website Quality & WQ1: Information Quality & WQ2: Security & \\
(WQ) & & WQ3: Convenience &
\end{tabular}

\section{Data Collection}

The survey was conducted in a major university in a large city of China. Subjects were randomly recruited from several major events on campus. A total number of 412 subjects were surveyed, with all cases responded. After deleting the answers with missing data, the number of final effective samples was 321 . The demographic data showed that males made up $50,8 \%$ of the total respondents. The respondents were predominantly young $(90,3 \%$ of them in the age group below 30-years and the majority is in their twenties) and generally well educated (94,7\% having attained at least an undergraduate diploma). Data indicated that the majority of respondents are new online purchase consumers, by the fact that about $64 \%$ reported their online purchase experience below 2 years. The samples match the university demographics well.

\section{Result}

To test the propose research model, data analyses for both the measurement model and structural model were performed using Partial Lease Square (PLS), and software SmartPLS (Ringle et al., 2005) was used to fulfill the calculation. Handling both formative and reflective indicator PLS analyzes structural equation models, including measurement and structural models with multi-item variables that contain direct, indirect and interaction effects (Chin, 1998b).

\section{Measurement Model}

For the evaluation of formative constructs measurement, we follow the guidelines provided by Chin (Chin, 1998a) and Diamantopoulos et al (Diamantopoulos \& Winklhofer, 2001). We first examined indicator weight to assess the strength of the relationship between each decomposed perceived risk and its risk dimensions. As shown in Table 3, all risk indicators except R4 (lack of good feel of product) were found to have significant path coefficients. Formative constructs are allowed to contain non-significant indicators, especially in the absence of multicollinearity (Mathieson et al., 2001). Dropping insignificant indicators may omit a unique part of the content domain (MacKenzie et al., 2005). The variance inflation factor (VIF) was then computed to assess multicollinearity. VIF values above 10 would suggest the existence of excessive multicollinearity and raise doubts about the validity of the formative measurement. As shown, the VIF varied from 1,128 to 2,198 , indicating that multicollinearity is not a concern in this study. Thus, all indicators remained in the following data analysis.

The assessment for reflective constructs included an estimation of internal consistency for reliability, tests for convergent and discriminant validity. Internal consistency was calculated using Cronbach's alpha and Fornell's composite reliability. It was suggested that Cronbach alpha higher than 0,60 and composite reliability higher 
than 0,7 are adequate. Average variance extracted (AVE) greater than 0,5 indicates that more than $50 \%$ of the variance of the measurement items can be accounted for by the constructs (Nunnally, 1967). As can be seen in Table 3, construct with reflective indicators well fit the requirements. Internal consistency is satisfied such that all composite reliabilities are higher than 0,7 , and the Cronbach's alpha for each construct is higher than 0.6. The bold face characters are the loadings of the items to its construct. It shows that the loadings are much higher than non-construct, indicating high internal consistency.

Table 3

Scale development

\begin{tabular}{|c|c|c|c|c|c|c|c|}
\hline \multicolumn{3}{|c|}{$\begin{array}{c}\text { Items Weights to } \\
\text { Formative Constructs }\end{array}$} & VIF & $\begin{array}{l}\text { Items Loadings to } \\
\text { Reflective Construct }\end{array}$ & $\begin{array}{l}\text { Re-purchase } \\
\text { Intention }\end{array}$ & SQ & WQ \\
\hline \multirow{3}{*}{$\begin{array}{l}\text { PR- } \\
\text { Cost }\end{array}$} & R1 & $0,323 * *$ & 1,154 & Possibility & 0,898 & 0,473 & 0,343 \\
\hline & $\mathrm{R} 2$ & $0,883 * *$ & 1,138 & Loyalty & 0,860 & 0,447 & 0,411 \\
\hline & R3 & $-0,133 * *$ & 1,128 & SQ1 & 0,495 & $\mathbf{0 , 8 7 1}$ & 0,590 \\
\hline \multirow{3}{*}{$\begin{array}{l}\text { PR- } \\
\text { Product }\end{array}$} & $\mathrm{R} 4$ & $0,751 * *$ & 1,326 & SQ2 & 0,409 & 0,848 & 0,484 \\
\hline & R5 & $-0,034$ & 1,128 & SQ3 & 0,351 & 0,699 & 0,383 \\
\hline & R6 & $0,427 * *$ & 1,315 & WQ1 & 0,329 & 0,429 & 0,794 \\
\hline \multirow{5}{*}{$\begin{array}{l}\text { PR- } \\
\text { Individual }\end{array}$} & R7 & $0,337 * *$ & 2,188 & WQ2 & 0,387 & 0,580 & $\mathbf{0 , 8 7 7}$ \\
\hline & $\mathrm{R} 8$ & $0,370 * *$ & 2,198 & WQ3 & 0,328 & 0,485 & 0,790 \\
\hline & R9 & $0,470 * *$ & 1,390 & Cronbach's $\alpha$ & 0,773 & 0,656 & 0,674 \\
\hline & & & & CR & 0,872 & 0,850 & 0,861 \\
\hline & & & & AVE & 0,773 & 0,656 & 0,674 \\
\hline
\end{tabular}

Discriminant validity was checked by examining whether the correlations between the variables were lower than the square root of the average variance extracted.
Table 4 indicates that all the square roots of each AVE value are greater than the off-diagonal elements. This indicates discriminant validity among constructs.

Correlations of latent variables.

\begin{tabular}{|c|c|c|c|c|c|c|c|c|}
\hline & Re-Purchase & PR-Cost & PR-Individual & PR-Product & Satisfaction & Benefit & SQ & WQ \\
\hline Re-Purchase & 0,879 & & & & & & & \\
\hline PR-Cost & $-0,238$ & -- & & & & & & \\
\hline $\begin{array}{l}\text { PR-Individua } \\
\text { l }\end{array}$ & $-0,429$ & 0,443 & - & & & & & \\
\hline PR-Product & 0,271 & 0,332 & 0,086 & - & & & & \\
\hline Satisfaction & 0,639 & $-0,271$ & $-0,320$ & 0,067 & 1,0 & & & \\
\hline Benefit & 0,572 & $-0,125$ & $-0,233$ & 0,115 & 0,572 & 1,0 & & \\
\hline SQ & 0,524 & $-0,088$ & $-0,242$ & 0,322 & 0,398 & 0,418 & $\mathbf{0 , 8 1 0}$ & \\
\hline WQ & 0,425 & $-0,077$ & $-0,193$ & 0,225 & 0,380 & 0,398 & 0,611 & 0,821 \\
\hline
\end{tabular}

To test the hypothesis, bootstrapping re-sampling Structure model procedure in SmartPLS was used to generate T-statistics and standard errors. Figure 2 presents the results for structural model.

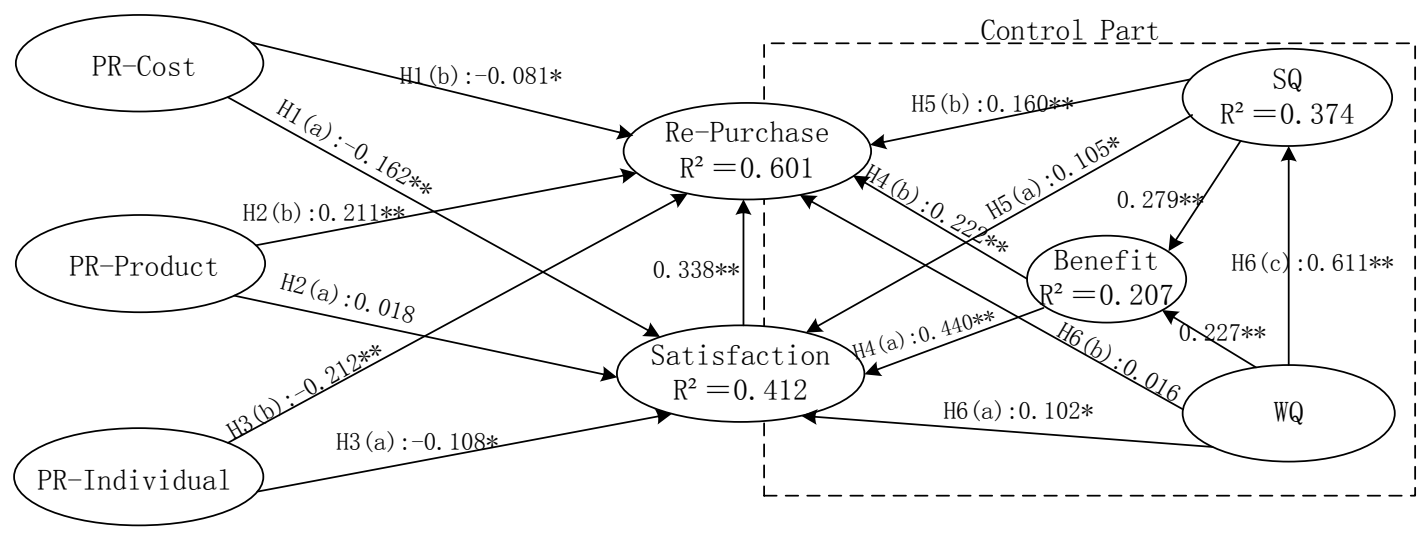

Figure 2. Hypothesis test for conceptual model.

(** Correlation is significant at the 0,01 level, with T-value (shown in ()) higher than 2,59; * Correlation is significant at the 0,05 level, with $\mathrm{T}$-value higher than 1,96; two-tailed.) 
Test result confirms most of the hypothesis. Consumers' satisfaction is powerful at explaining their re-purchase intention, with coefficient of 0,338 . Perceived cost risk was found to have a negative impact on consumers' satisfaction $(b=-0,162, p<0,01)$, but lighter effect to re-purchase intention, $(b=-0,081, p<0,05)$. Contrary to our assumptions, the perceived product risk was found to have no significant effect on satisfaction $(\mathrm{T}=0,39<1,96)$ but had a positive impact on the re-purchase intention $(b=0,211, p<0,01)$. This result, especially the positive effect is rather counter-intuitive to existing theory of perceived risk, and will be discussed later. The perceived individual anxiety risk, as we assumed, was found to have a significant negative effect to both satisfaction $(b=-0,108, p<0,05)$ and re-purchase intention $(b=-0,212, p<0,01)$. The result implies each part of decomposed perceived risk had respective effect on consumers' purchase behavior.

Results also support most of the hypotheses we proposed in control part. Consumers' overall perceived benefit was found to have significant predictive power to their satisfaction $(b=0,440, p<0.01)$ and re-purchase intention $(b=0,222, p<0,01)$. Service quality had direct influence on consumers' satisfaction and re-purchase intention $\quad(b=0,105, \quad p<0,05 ; \quad b=0,160, \quad p<0,01$; respectively). Website quality was found to have a direct positive impact on satisfaction $(b=0,102, p<0,05)$, but no direct impact on re-purchase intention (T-value $=0,385<1,96)$. The high correlation between service quality and website quality $(0,611)$ and high R-square for service quality $(0,374)$ indicated that website quality had strong predictive power to service quality in e-commerce. Vendor's service quality and website quality were found to have positive effects on consumers' perceived benefit $(b=0,279, \quad p<0,01 ; b=0,227, \quad p<0,01$; respectively). Thus the mediating roles that perceived benefit played between website/service quality and satisfaction/ re-purchase intention were confirmed: perceived benefit partially mediated the relationships of service quality-> satisfaction, service quality-> re-purchase intention and website quality->satisfaction, whilst played full mediating role in website quality->re-purchase intention. The $\mathrm{R}$ square of Satisfaction and Re-Purchase intention (0,411, 0,601, respectively) tells that the models provides strong explanations of the variance in consumer satisfaction and re-purchase intention. Besides, we've done moderating effects test for the employed demographic variables as control variables to see whether they were boundary conditions for these verified relationships. Results showed no significant moderating effect.

\section{Discussion and Conclusion}

Online purchases are recognized inherently risky. Yet researchers have not systematically explored how different sources of perceived risk operate in an online purchase behavior. To get a better understanding of perceived risk, in this research, we proposed a new way to decompose the perceived risk and then test the respective role of each decomposed part. The perceived risk was decomposed to come from three main transaction elements: transaction process, product and the individual anxiety. In the conceptual research model, customer satisfaction and re-purchase intention were used as different antecedents of purchase behaviors, and service quality, website quality and overall perceived benefits were introduced as control part. The various sources of perceived risk were examined on their respective roles in influencing consumers' online purchasing behaviors based on this model.

The empirical results suggest that, different parts of decomposed risks have distinct impacts on consumers' online purchase behavior. Perceived transaction cost risk was found to have a negative effect on satisfaction but lighter significant effect on re-purchase intention. The perceived individual anxiety risk was found to have strong negative effects on both satisfaction and re-purchase intention. This result suggests that consumers' experienced negative satisfaction partly comes from transaction cost risk and partly comes from the risk of physical and psychology pressure, but seems not to be related with product risk.

More interestingly, the product oriented risk was found to have positive effects on re-purchase intention, which runs counter to most existing research result. We infer several possible reasons. One is that cheaper price benefit stimulates high product-risk attempts. In most cases, higher product risk products often come with cheaper prices. To some consumers, paying a lower price for a product is actually a type of major benefit. When the benefit from price advantage exceeds the potential risk brought by the low quality product, consumers still tend to accept a probably problematic product (i.e. off brand/imitated products) as long as the product can still fulfill his/her functional needs. In other words, though people know low price could mean high product risk, they still show high desire to try it. "The higher the consumer's perception of the risk associated with shopping on the Internet, the higher would be their perception of the variance or uncertainty in the benefits derived. If the consumers think shopping on the Internet is highly risky, they would expect a large variance in the utility from shopping on the Internet", has also been stated by Bhatnagar et al (Bhatnagar et al., 2000). Especially, the "Shanzhai" phenomenon is quite prevailing in the Chinese market. "Shanzhai" products refer to Chinese imitation and pirated brands and goods, particularly consumer electronics products. All "Shanzhai" products hold characteristics of low price and full-fledged in functionality, while the quality depends - some even are comparable with big-name brands, some are totally in poor quality. Since this quality uncertainty exists, people who are price sensitive show desire to try. Secondly, a unique payment mechanism in China-Cash on Delivery (COD) even makes product risk not an issue even if the consumer considers it a problematic product before payment. The COD means that the consumers only make the payment when they receive the products and finish the examination of the products. It allows consumers to refuse to pay and reject the shipment if they were not satisfied with the products. If a customer finds the product is in poor quality, fake goods or has some other problems once received the product, he/she can refuse to pay, and no loss was taken by customer. The COD mechanism can thus effectively mitigate the impacts of perceived product risk. Taken 
together, to gamble a possible above value purchase, perceived product risk (always come up with low price) stimulates the high purchase intention.

Service quality, website quality and overall perceived benefit were introduced as control variables. Purchase intention was found to be mainly influenced service quality while website quality showed little effects. To the contrary, satisfaction was found to be more influenced by website quality than service quality. It can be understood that satisfaction is more direct perception than re-purchase intention, relying much on directly perceivable website quality; re-purchase intention is relatively a more deliberative decision, concerning more about overall service quality from all aspects of vendor reputation, after-sale and privacy protect et al. This result is slightly different from IS Success Model, which states service quality, information quality and system quality are effective antecedents of satisfaction and re-use intention. We thought these minor differences might also come from not well-rounded e-commerce market of China. As has been mentioned earlier, Chinese e-commerce vendors use some unique assurance mechanisms to attract people and improve user experience, like COD, freight insurance et al. Most of the mechanisms will help mitigate consumers' loss or potential risks. All of these mechanisms are considered as part of service quality, while the website quality has no specific guarantee or advantage. So when asked about purchase intention, service quality shows to have more predictive power than website quality. Overall perceived benefit was found to play a mediating role in the relationships among the service quality, website quality, satisfaction and re-purchase intention. All connections were significant, indicating that the overall perceived benefit has an indirect effect on satisfaction and re-purchase intention.

\section{Theoretical and practical contributions}

This study has both theoretical and practical contributions. From a theoretical perspective, a new perceived risk classification method from value transfer elements was proposed. Most existing research examined the effect of the integrated risk at an overall higher level or at a detailed risk facets level, while our study provides considerable work in decomposing risk in accordance with transaction elements. We view a transaction as a process of value transfer which is comprised by three elements: product, people and transaction process. Perceived risks existing in a transaction are correspondingly decomposed into product risk, individual risk and transaction cost risk. This new perspective of investigating perceived risk overcomes the limitations of measurement of risk only on a high level or too complicated classification schemes in existing research studies. By distinguishing among the concepts both conceptually and empirically, we believe we've provided important insights into their distinct roles in the online purchase process. This classification method makes empirical test feasible. A model was proposed to test the role of each decomposed risk plays in affecting consumers' satisfaction and in influencing re-purchase intention, respectively. This study helps better understand the property of each transaction involving elements. In addition, consumers' satisfaction and re-purchase intention are proposed to represent consumers' different antecedents of purchase behavior, and were proved to be influenced by different risks. Moreover, with several relevant online purchase influential factors introduced in as control variables, this research provides a holistic model of online purchase risk research.

From a practical standpoint, the results highlight several types of perceived risk that may significantly influence the successful completion of electronic commerce transactions. The risks perceived from different transaction components have their respective roles in influencing consumers' satisfaction and final re-purchase intention. The results offer several implications to the online vendors. First, suppliers should consider decrease level of consumers' risk perception by providing more competitive price, appropriate description of product and better security guarantee service, which will finally promote consumer satisfaction; whilst better individual risk concern can also increase consumers' re-purchase intention. Secondly, since the distinct COD payment method exists, the China individual-vendors in the $\mathrm{C} 2 \mathrm{C}$ market should consider opening cash on delivery service as the B2C does, for it can increase the sale possibilities. Thirdly, service quality was found quite important in increasing customer re-purchase intention while website quality bringing customer satisfaction. Internet business managers should pay particular attention to these factors in order to increase transaction volume and guarantee the success ratio.

\section{Limitations and directions for future research}

As with any research, care should be taken when generalizing the results of this study. This study does not control the differences across product categories, while products with different properties may lead to varying customers risk perception and different purchase behavior. E-commerce channels (B2C or C2C) were not differentiated either, for different channels may bring different transaction and settlement procedures. In addition, consumers' internet usage habit might influence their cognition of online purchase and lead to diverse purchase behavior. These questions need to be examined in future research.

\section{Appendix: Variables and Questions}

\section{Satisfaction:}

Based on your prior experience, please evaluate your overall satisfaction toward online shopping. (1-7, from absolutely disappointed to fully satisfied). 
Yue Chen, Xiangbin Yan, Weiguo Fan. Examining the Effects of Decomposed Perceived Risk on Consumer Online...

\section{Repurchase intention:}

1. Based on your experience, please indicate the possibility of your online purchase in the future. (1-7, from absolutely no to be certain will).

2. Will you consider purchasing in the same internet shop that you have previously bought? (1-7, from absolutely no to be certain will).

\section{Perceived Risk:}

1. I am worried that the price online may be higher than that in mall. (PR-Cost)

2. I am worried that the seller will not send me the commodity immediately after I have paid. (PR-Cost)

3. I am worried that the online shopping will take me too much time in searching and comparing. (PR-Cost)

4. I am worried about the quality of the products sold on line, e.g. fake, smuggled goods, reprocessed product. (PR-Product)

5. I am worried that the products I bought online do not meet my requirement due to lack of good feel of the actual product. (PR-Product)

6. I am worried about the true value of the product I bought online is lower than my expectation. (PR-Product)

7. I am worried that the online shopping will do harm to my physical and psychological health. (PR- Individual)

8. I am worried that my private information will be leaked. (PR-Individual)

9. I am worried that the online shopping may give me higher mental pressure and social pressure. (PR- Individual)

\section{Website Quality:}

1. I always choose the website in good design.

2. I always choose the website that can ensure my private information security.

3. I always choose the website which can provide detailed instruction, specific consulting.

\section{Service Quality:}

1. I always choose the vendor who has high reputation.

2. I always choose the vendor who can protect the privacy security to consumer.

3. I always choose the vendor who provides good after-sale services.

\section{Perceived Benefit:}

According to previous experience, how do you evaluate the overall online purchasing benefit? (Like more convenience than bricks-and-mortar purchase, the price is always more seductive, possible to buy some things rarely seen in mall, et al. 1-7, from no benefit to very high--almost satisfy your maximum expectation.)

\section{References}

Ajzen, I. (1991). The theory of planned behavior. Organizational behavior and human decision processes, 50(2), $179-211$. http://dx.doi.org/10.1016/0749-5978(91)90020-T

Barnes, S. J. (2002). The mobile commerce value chain: analysis and future developments. International Journal of Information Management, 22(2), 91-108. http://dx.doi.org/10.1016/S0268-4012(01)00047-0

Bauer, R. A. (1960). Consumer behavior as risk taking. Dynamic marketing for a changing world, 398.

Bhatnagar, A., Misra, S., \& Rao, H. R. (2000). On risk, convenience, and Internet shopping behavior. Communications of the ACM, 43(11), 98-105. http://dx.doi.org/10.1145/353360.353371

Bhattacherjee, A. (2001). Understanding information systems continuance: an expectation-confirmation model. MIS quarterly, 25(3), 351-370. http://dx.doi.org/10.2307/3250921

Brynjolfsson, E., \& Smith, M. D. (2000). Frictionless commerce? A comparison of Internet and conventional retailers. Management Science, 46(4), 563-585. http://dx.doi.org/10.1287/mnsc.46.4.563.12061

Chin, W. W. (1998a). Commentary: Issues and opinion on structural equation modeling. MIS quarterly.

Chin, W. W. (1998b). The partial least squares approach to structural equation modeling. Modern methods for business research, 295, 336.

Coase, R. H. (1988). The nature of the firm: influence. Journal of Law, Economics, \& Organization, 4(1), $33-47$.

Cox, D. F. (1967). Risk taking and information handling in consumer behavior: Division of Research, Graduate School of Business Administration, Harvard University. http://dx.doi.org/10.1108/02656710210434784Cox, J., \& Dale, B. (2002). Key quality factors in Web site design and use: an examination. International Journal of Quality \& Reliability Management, 19(7), 862-888.

Culnan, M. J., \& Armstrong, P. K. (1999). Information privacy concerns, procedural fairness, and impersonal trust: An empirical investigation. Organization Science, 10(1), 104-115. http://dx.doi.org/10.1287/orsc.10.1.104

Cunningham, S. M. (1967). The major dimensions of perceived risk. Risk taking and information handling in consumer behavior, 82-108.

Davis, F. D., Bagozzi, R. P., \& Warshaw, P. R. (1989). User acceptance of computer technology: a comparison of two 
theoretical models. Management Science, 35(8), 982-1003. http://dx.doi.org/10.1287/mnsc.35.8.982

Delone, W. H. (2003). The DeLone and McLean model of information systems success: a ten-year update. Journal of management information systems, 19(4), 9-30.

DeLone, W. H., \& McLean, E. R. (1992). Information systems success: the quest for the dependent variable. Information systems research, 3(1), 60-95. http://dx.doi.org/10.1287/isre.3.1.60

Diamantopoulos, A., \& Winklhofer, H. M. (2001). Index construction with formative indicators: an alternative to scale development. Journal of marketing research, 38(2), 269-277. http://dx.doi.org/10.1509/jmkr.38.2.269.18845

Dowling, G. R. (1986). Perceived risk: the concept and its measurement. Psychology \& Marketing, 3(3), $193-210$. http://dx.doi.org/10.1002/mar.4220030307

E, W. O. (1985). The Economic Institutions of Capitalism Firms Markets Relational Contracting: Free Press.

Ethier, J., Hadaya, P., Talbot, J., \& Cadieux, J. (2006). B2C Web site quality and emotions during online shopping episodes: an empirical study. Information \& Management, 43(5), 627-639. http://dx.doi.org/10.1016/j.im.2006.03.004

Featherman, M. S., \& Pavlou, P. A. (2003). Predicting e-services adoption: a perceived risk facets perspective. International Journal of Human-Computer Studies, 59(4), 451-474. http://dx.doi.org/10.1016/S1071-5819 (03)00111-3

Fishbein, M., \& Ajzen, I. (1975). Belief, attitude, intention and behavior: An introduction to theory and research.

Gefen, D. (2000). E-commerce: the role of familiarity and trust. Omega, 28(6), 725-737. http://dx.doi.org/10. 1016/S0305-0483(00)00021-9

Glover, S., \& Benbasat, I. (2010). A comprehensive model of perceived risk of e-commerce transactions. International journal of electronic commerce, 15(2), 47-78. http://dx.doi.org/10.2753/JEC1086-4415150202

Greenstein, M., \& Feinman, T. M. (2000). Electronic commerce: Security, risk management, and control: Irwin/McGraw-Hill.

Hoffman, D. L., Novak, T. P., \& Peralta, M. (1999). Building consumer trust online. Communications of the ACM, 42(4), 80-85. http://dx.doi.org/10.1145/299157.299175

Howard, J. A., \& Sheth, J. N. (1969). The theory of buyer behavior.

Jacoby, J., \& Kaplan, L. B. (1972). The components of perceived risk. Advances in consumer research, 3(3), 382-383.

Jarvenpaa, S. L., \& Todd, P. A. (1996). Consumer reactions to electronic shopping on the World Wide Web. International journal of electronic commerce, 59-88.

Jarvis, C. B., MacKenzie, S. B., \& Podsakoff, P. M. (2003). A critical review of construct indicators and measurement model misspecification in marketing and consumer research. Journal of consumer research, 30(2), $199-218$. http://dx.doi.org/10.1086/376806

Kazakeviciute, A., \& Banyte, J. (2012). The Relationship of Consumers Perceived Hedonic Value and Behavior. [Article]. Inzinerine Ekonomika-Engineering Economics, 23(5), 532-540. doi: 10.5755/j01.ee.23.5.1975 http://dx.doi.org /10.5755/j01.ee.23.5.1975

Kim, D. J., Ferrin, D. L., \& Rao, H. R. (2008). A trust-based consumer decision-making model in electronic commerce: The role of trust, perceived risk, and their antecedents. Decision support systems, 44(2), 544-564. http://dx.doi.org/10.1016/j.dss.2007.07.001

Kwak, H., Fox, R. J., \& Zinkhan, G. M. (2002). What products can be successfully promoted and sold via the Internet? Journal of advertising research, 42(1), 23-38.

Liang, T.-P., \& Huang, J.-S. (1998). An empirical study on consumer acceptance of products in electronic markets: a transaction cost model. Decision support systems, 24(1), 29-43. http://dx.doi.org/10.1016/S0167 -9236 (98)00061-X

Lim, N. (2003). Consumers' perceived risk: sources versus consequences. Electronic Commerce Research and Applications, 2(3), 216-228. http://dx.doi.org/10.1016/S1567-4223(03)00025-5

Luo, X., Li, H., Zhang, J., \& Shim, J. (2010). Examining multi-dimensional trust and multi-faceted risk in initial acceptance of emerging technologies: An empirical study of mobile banking services. Decision support systems, 49(2), 222-234. http://dx.doi.org/10.1016/j.dss.2010.02.008

MacKenzie, S. B., Podsakoff, P. M., \& Jarvis, C. B. (2005). The problem of measurement model misspecification in behavioral and organizational research and some recommended solutions. Journal of Applied Psychology, 90(4), 710-730. http://dx.doi.org/10.1037/0021-9010.90.4.710

Mathieson, K., Peacock, E., \& Chin, W. W. (2001). Extending the technology acceptance model: the influence of perceived user resources. ACM SIGMIS Database, 32(3), 86-112. http://dx.doi.org/10.1145/506724.506730

Mitchell, V. W. (1992). Understanding consumers' behaviour: can perceived risk theory help? Management Decision, 30(3). http://dx.doi.org/10.1108/00251749210013050 
Yue Chen, Xiangbin Yan, Weiguo Fan. Examining the Effects of Decomposed Perceived Risk on Consumer Online...

Mitchell, V. W. (1999). Consumer perceived risk: conceptualisations and models. European Journal of marketing, 33(1/2), 163-195. http://dx.doi.org/10.1108/03090569910249229

Mowen, J. C. (1992). The time and outcome valuation model: Implications for understanding reactance and risky choices in consumer decision making. Advances in consumer research, 19, 182-189.

Narayandas, D. (2005). Building loyalty in business markets. Harvard Business Review, 83(9), 131-139.

Nunnally, J. C. (1967). Psychometric theory: Tata McGraw-Hill Education.

Oliver, R. L. (1980). A cognitive model of the antecedents and consequences of satisfaction decisions. Journal of marketing research, 460-469. http://dx.doi.org/10.2307/3150499

Oliver, R. L. (1999). Whence consumer loyalty? The Journal of Marketing, 33-44. http://dx.doi.org/10.2307/1252099

Park, C. H., \& Kim, Y. G. (2003). Identifying key factors affecting consumer purchase behavior in an online shopping context. International Journal of Retail \& Distribution Management, 31(1), 16-29. http://dx.doi.org/10.1108/ 09590550310457818

Pavlou, P. A. (2003). Consumer acceptance of electronic commerce: Integrating trust and risk with the technology acceptance model. International journal of electronic commerce, 7(3), 101-134.

Pires, G., Stanton, J., \& Eckford, A. (2004). Influences on the perceived risk of purchasing online. Journal of Consumer Behaviour, 4(2), 118-131. http://dx.doi.org/10.1002/cb.163

Ringle, C. M., Wende, S., \& Will, A. (2005). SmartPLS 2.0 (beta).

Roselius, T. (1971). Consumer rankings of risk reduction methods. The Journal of Marketing, 56-61. http://dx.doi.org/10. $2307 / 1250565$

Salciuviene, L., Auruskeviciene, V., \& Ivanauskiene, N. (2014). Key Drivers Affecting Customer Intention to Purchase Financial Services Online. Inzinerine Ekonomika-Engineering Economics, 25(2), 194-202. http://dx.doi.org/10. 5755/j01.ee.25.2.6427

Shim, S., \& Mahoney, M. Y. (1992). Differentiation of Satisfied Users and Dissatisfied Users of In-Home Electronic Shopping Mode: An Exploratory Study. way, 5, 193.

Simpson, L., \& Lakner, H. B. (1993). Perceived risk and mail order shopping for apparel. Journal of Consumer Studies \& Home Economics, 17(4), 377-389. http://dx.doi.org/10.1111/j.1470-6431.1993.tb00180.x

Venkatraman, M. P. (1989). Involvement and risk. Psychology and Marketing, 6(3), 229-247. http://dx.doi.org/10. 1002/mar.4220060306

Verhagen, T., \& van Dolen, W. (2011). The influence of online store beliefs on consumer online impulse buying: A model and empirical application. Information \& Management, 48(8), 320-327. http://dx.doi.org/10.1016/j.im2011. 08.001

Williamson, O. E. (1981). The economics of organization: the transaction cost approach. American journal of sociology, 548-577. http://dx.doi.org/10.1086/227496

Yan, X., \& Dai, S. (2009). Consumer's Online Shopping Influence Factors and Decision-Making Model. Value Creation in E-Business Management, 89-102. http://dx.doi.org/10.1007/978-3-642-03132-8_8

Yang, Z., \& Peterson, R. T. (2004). Customer perceived value, satisfaction, and loyalty: the role of switching costs. Psychology \& Marketing, 21(10), 799-822. http://dx.doi.org/10.1002/mar.20030

Zeithaml, V. A. (1988). Consumer perceptions of price, quality, and value: a means-end model and synthesis of evidence. The Journal of Marketing, 52(3), 2-22. http://dx.doi.org/10.2307/1251446

The article has been reviewed.

Received in October, 2014; accepted in April, 2015. 